\title{
$=\mathrm{T} R A M A=$
}

\section{AFROEMPREENDEDORISMO FEMININO: OS SENTIDOS DA EXPRESSÃO “MULHER NEGRA" NUMA REVISTA FEMININA}

\author{
JÚLIA BOMFIM COSTA (UESB) 1 \\ https://orcid.org/0000-0001-5735-3526
ADILSON VENTURA DA SILVA (UESB) ${ }^{2}$
http://orcid.org/0000-0001-7521-3981

\begin{abstract}
RESUMO: Pretendemos, neste trabalho, analisar os sentidos de mulher negra presentes na discussão sobre o tema afroempreendedorismo feminino promovido pela revista Cláudia. Para esta análise, utilizamos o aporte teórico da Semântica do Acontecimento, partindo da premissa de que os sentidos são constituídos na enunciação, no acontecimento do dizer. Com isso, os recortes escolhidos para análise, retirados da matéria "Sob Nova Direção", edição de Novembro/2019, expõe depoimentos de mulheres negras que alcançaram reconhecimento como empreendedoras e nos mostram a constituição de memoráveis que apontam para questões de raça e classe. Além desse funcionamento, a análise mostra a presença de um conflito frente aos sentidos relacionados a aspectos financeiros. Com isso, chegamos ao Domínio Semântico de Determinação (DSD) que aponta a mulher negra sendo determinada pelo afroempreendedorismo que, por sua vez, é determinado pelo poder financeiro.
\end{abstract}

PALAVRAS-CHAVE: Mulher negra. Sentidos. Negócios.

ABSTRACT: It is intended in this work to analyze the senses of black women present in the discussion on the topic of female afro-entrepreneurship promoted by Cláudia magazine. For this analysis we use the theoretical contribution of the Semantic Event, starting from the premise that the senses are constituted in the enunciation, in the event of the saying. With this, the clippings chosen for analysis, taken from the article "Under New Direction", November/2019 edition, exposes testimonies of black women who have achieved recognition as entrepreneurs and show us the constitution of memorables that point to issues of race and class. Besides this functioning, we still have a conflict with senses related to financial aspects, which superimposes these senses over the others observed in this materiality. With this, we arrive at the DSD, which points out the black woman being determined by afro-entrepreneurship, which in turn is determined by financial power.

KEYWORDS: Black woman. Senses. Business.

\section{INTRODUÇÃO}

Pensar as diferenças que caracterizam as mulheres entre si sempre foi um desafio quando os seus direitos eram postos em discussão. Superar tal desafio significou, em certa medida, perceber que a perspectiva da universalidade da categoria mulher acaba por criar invisibilidades que apagam as diferenças existentes dentro do próprio gênero. Essa análise simplista imposta por um pensamento colonial e dominador de supremacia branca, impossibilita

\footnotetext{
${ }^{1}$ Mestranda do Programa de Pós Graduação em Linguística (PPGlin), membro do Grupo de Estudo e Pesquisa em Semântica (Gepes).E-mail: bomfim.c.julia@gmail.com

2 Professor, Doutor em Linguística, na Universidade Estadual do Sudoeste da Bahia (UESB/DELL/PPGLin/Profletras/Gepes). E-mail: adilson.ventura@gmail.com
} 


\section{$=$ TRAMA $=$}

que se tenha um olhar interseccional acerca das questões de raça, classe e orientação sexual, excluindo as diferentes experiências vivenciadas pelas mulheres e seus marcadores de identidade social.

Nesse contexto, teóricas feministas como bell hooks ${ }^{3}$ (2019), Djamila Ribeiro (2019) e Kimberlé Crenshaw (2004) destacam a raça como a diferença que mais distanciava as mulheres entre si, sobretudo pelos efeitos da discriminação que, por vezes, impediam que as mulheres negras fossem ouvidas. O desafio desde então, segundo Crenshaw (2004), foi incorporar a perspectiva de gênero nos discursos dos direitos humanos e trazer a questão de raça ao gênero. Essa perspectiva mais atenta chamou a atenção para as questões que invisibilizam as mulheres negras enquanto sujeitos políticos, tendo em vista que, de acordo com Grada Kilomba (apud RIBEIRO, 2019), essas mulheres têm sua realidade deturpada por outros discursos, ou seja, quando se trata de gênero, fala-se da mulher branca, já quando a discussão aborda questões raciais, o sujeito torna-se o homem negro; tendo, assim, a mulher negra um lugar de exclusão e apagamento de vozes.

Esta problemática se constitui ao modo que, "por causa de sua identidade interseccional como mulheres e não-brancas dentro de discursos que são moldados para responder a um ou outro, mulheres não-brancas são marginalizadas dentro de ambos" (CRENSHAW, 1991 p. 2) ${ }^{4}$. Dessa forma, deparamo-nos com duas categorias - de gênero e de raça - que se cruzam, ou formam interseccionalidades ${ }^{5}$, e juntas criam outras formas de opressão. Esse raciocínio, segundo Crenshaw (2004), não só destaca que mulheres negras enfrentam situações diferentes daquelas enfrentadas por mulheres brancas ou por homens negros como também caracterizam um cenário em que a intersecção dos marcadores de sua identidade social condiciona e, por vezes, limita as suas ações na sociedade.

Atualmente, a forma de pensar a mulher negra aponta para o recorte de diversos memoráveis em que ainda é possível interpretar a presença de um pensamento hegemônico pautado no racismo e na submissão. Esse pensamento está carregado de sentidos que se encontram incutidos em determinados modos de representações sociais que são instituídos no tempo pelo senso comum. E, embora a televisão e as revistas não sejam mais as mesmas desde o início da militância de bell hooks, em que a figura da mulher branca predominava na mídia, ainda é preciso entender como a figura da mulher negra é evidenciada e quais sentidos circulam na sua representação.

Desta forma, entendendo que a mídia e os diversos meios de comunicação colaboram veementemente para disseminação de representações de ideias e sujeitos, este trabalho analisa os sentidos de mulher negra em uma revista de grande circulação voltada para o público feminino, visto o potencial da indústria da moda em ditar padrões estéticos e apresentar estilos de vida. Contudo, pensou-se em examinar como, dentro do universo midiático feminino, os sentidos de mulher negra são constituídos, considerando a presença dessa figura no conteúdo produzido pela revista, o tipo de publicação em que aparecem e os enunciados que caracterizam essa mulher.

\footnotetext{
${ }^{3}$ Pseudônimo utilizado por Gloria Jean Watkins. Segundo a autora, é grafado em letras minúsculas a fim de deslocar o foco da figura autoral para suas ideias.

${ }^{4}$ Tradução de Carol Correia. Disponível em

$<$ https://negrasoulblog.files.wordpress.com/2016/04/mapping-the-margins-intersectionality-identity-politicsand-violence-against-women-of-color-kimberle-crenshaw1.pdf> Em 29/10/2019.

${ }^{5}$ A Interseccionalidade "trata especificamente da forma pela qual o racismo, o patriarcalismo, a opressão de classe e outros sistemas discriminatórios criam desigualdades básicas que estruturam as posições relativas de mulheres, raças, etnias, classes e outras" (CRENSHAW, 2002, p.177).
} 


\section{$=$ TRAMA $=$}

Para a realização da análise, foi escolhida a Revista Cláudia, da Editora Abril, edição de Novembro de 2019 - mês em que se comemora o Dia da Consciência Negra - da qual escolhemos analisar umas das matérias em destaque na capa, apresentando a seguinte chamada: "Poder Afro - Mulheres negras transformam a falta de oportunidades em negócios". Sendo assim, buscou-se compreender, a partir dos sentidos de mulher negra instaurados naquela materialidade, qual o "poder" que a revista atribui a essas mulheres. No interior da revista, a matéria analisada, que recebe o título de "Sob Nova Direção", traz a discussão acerca da dificuldade de mulheres negras conseguirem oportunidades de emprego e como elas passaram a utilizar sua realidade para buscar alternativas no afroempreendedorismo feminino. Para tanto, o periódico apresenta o depoimento de cinco mulheres negras abordando suas experiências enquanto empreendedoras, na luta por mais representatividade, valorização da cultura afro e mais oportunidades.

O desenvolvimento desta análise contou com o aporte teórico da Semântica do Acontecimento (SA), teoria semântica enunciativa proposta pelo professor da Unicamp Eduardo Guimarães $(1995,2002,2009,2018)$, que parte da premissa de que os sentidos são constituídos na enunciação, numa relação da língua com a própria língua, enquanto algo que é tomado na temporalidade do acontecimento.

\section{A SEMÂNTICA DO ACONTECIMENTO}

Partindo do interesse central do estudo da significação da linguagem, a Semântica do Acontecimento (SA) volta-se, especificamente, para a análise dos sentidos constituídos enunciativamente. Para tanto, visto que a língua é posta em funcionamento ao passo em que enunciamos, tomamos a enunciação como um acontecimento de linguagem que se estabelece na relação entre o sujeito e a língua. Portanto, segundo Guimarães (2002, p. 7), "a análise do sentido da linguagem deve localizar-se no estudo da enunciação, do acontecimento do dizer".

Para compreendermos melhor a SA, é fundamental a concepção de que a língua não é transparente. Assim, o que queremos propor com isso é que os sentidos não são fixos e nem significarão o mesmo todas as vezes em que forem enunciados, mas é necessário pensar que a significação de uma forma linguística é tomada como parte da constituição de sentido de um enunciado e suas relações de integração entre os elementos de um texto e com o que é exterior à língua. Desse modo, como propõe Guimarães (2018, p. 22), "a significação é considerada aqui como o sentido dos enunciados que se produz neste acontecimento do funcionamento da língua".

Para a conceituação do acontecimento, é preciso considerar, além da relação do sujeito com a língua, outros dois elementos decisivos: o real e a temporalidade. O primeiro, "a que o dizer se expõe ao falar dele" (GUIMARÃES, 2002, p. 11), trata-se de uma materialidade histórica, a qual se considera a língua como um sistema de regularidades afetado pelo simbólico, entendendo que o sentido é constituído historicamente. Já o segundo elemento, a temporalidade, nos permite compreender que não é o sujeito que temporaliza, este não é a origem do tempo do enunciado, visto que a sua enunciação é sempre um re-dito de outras enunciações. É, portanto, o acontecimento que cria sua própria temporalidade. Nessa direção, Guimarães (2002, p. 12) conceitua assim o acontecimento como "a diferença na sua própria ordem: o acontecimento é sempre uma nova temporalização, um novo espaço de conviviabilidade de tempos, sem a qual não há sentido, não há acontecimento de linguagem, não há enunciação".

Nessa perspectiva, o que é enunciado no presente está significando porque mobiliza tempos distintos, ou seja, ao enunciar, o acontecimento recorta um passado e projeta um futuro de sentidos, em que existem sempre outras possibilidades de interpretação. É importante frisar 


\section{$=$ TRAMA $=$}

que o passado, nesse caso, não é uma lembrança de um fato anterior, mas uma rememoração de enunciações, é o resgate de um memorável recortado pelo próprio acontecimento. Guimarães (2018) trata a questão da temporalidade enquanto uma disparidade de tempos entre o acontecimento e a representação da temporalidade do sujeito que enuncia.

Outro ponto importante a considerar é tratar o acontecimento de linguagem como uma prática política que instala um conflito no centro do dizer. Nesse sentido, o político é para nós, não a conceituação da igualdade ou concessão de direitos e deveres, mas a sua essência está centrada nas relações sociais que têm como um de seus fundamentos a linguagem. Conforme Guimarães (2002), o político é, assim, a contradição de uma normatividade que se divide, se transforma e se redivide incessantemente em nome da afirmação de pertencimento de todos, pelo direito de dizer.

Desse modo, entendemos que o acontecimento de linguagem é político, porque se dá num espaço de enunciação, regulado pela relação entre línguas e sujeitos determinados pelas línguas que falam, chamados nessa configuração de falantes. Assim, a disputa pela palavra é determinada nesse espaço por uma "[...] deontologia que organiza e distribui papéis, e do conflito, indissociado desta deontologia, que redivide o sensível, os papéis sociais" (GUIMARÃES, 2002, p. 18).

A divisão desse espaço político nos apresenta configurações locais específicas de acesso à palavra, as cenas enunciativas, nas quais se caracterizam as relações entre as figuras da enunciação e as formas linguísticas. Dentre esta relação, destacamos as figuras do Locutor e do locutor-x que, respectivamente, definem o lugar do sujeito, origem do dizer, e o lugar social do dizer que agencia o Locutor. Em determinados momentos, no entanto, não é possível identificar de qual lugar social do dizer o Locutor enuncia. Nesse caso, o Locutor é tomado por um lugar do dizer de enunciador, divididos por: enunciador-individual, enunciador-genérico, enunciador-universal e enunciador-coletivo. O enunciador-individual enuncia a partir do lugar do "eu", representando a individualidade do lugar de dizer. O enunciador-genérico ocorre partir da enunciação de um ditado popular, reproduzindo o sentido expresso no ditado como aquilo que é enunciado por todos. O enunciador-universal enuncia tomando como referência o mundo, estabelecendo uma relação de verdadeiro/falso entre o que se diz com os fatos. Já o enunciador-coletivo ocupa um lugar comum determinado pela coletividade do dizer de um grupo específico (GUIMARÃES, 2018).

\section{PROCEDIMENTOS DE ANÁLISE DA SA}

Para o desenvolvimento de análises voltadas para os sentidos de expressões constituídas enunciativamente, conforme os preceitos da SA, é preciso que consideremos as relações de uma forma linguística em um enunciado, enquanto parte do texto que o integra. Para tanto, este trabalho apoia-se na utilização dos procedimentos de Reescritura e Articulação para observar quais os sentidos de mulher negra estão constituídos na materialidade analisada.

A reescritura, considerando que os sentidos estão dispersos no texto, consiste no "modo de relação pelo qual a enunciação rediz o que já foi dito" (GUIMARÃES, 2018, p. 85), na medida em que, ao retomar outros elementos do texto, a reescritura passa a significar de um outro modo. Guimarães considera que a reescritura acontece de diferentes modos, são eles: 1) repetição; estabelece uma relação de sentido correspondente à sinonímia ou hiperonímia. 2) substituição; corresponde às relações de reescrituração que se estabelecem por meio de uma especificação ou definição do termo. 3) expansão; é equivalente às reescriturações resultantes do desenvolvimento, generalização ou enumeração do termo ou expressões reescriturados. 4) condensação; de modo contrário à expansão, ocorre quando a reescrituração é resultado da generalização dos termos reescriturados. 


\section{$=$ TRAMA $=$}

Já a articulação é entendida como "um modo de relação enunciativa que dá sentido às contiguidades linguísticas, é, então, uma relação local entre os elementos linguísticos que significam pela relação com os lugares da enunciação agenciados pelo acontecimento" (GUIMARÃES, 2018, p. 80). Desse modo, a articulação funciona a partir dos modos pelos quais essas relações organizam o texto, desenvolvendo-se de três maneiras: por dependência, quando um elemento se vincula a outro elemento contíguo, constituindo um único elemento; coordenação, quando ocorre um processo de acúmulo entre os elementos contíguos, tomando palavras ou enunciados distintos em uma só natureza; e por incidência, quando um elemento se vincula a outro distinto e produz uma modificação de sentido.

\section{ANÁLISES}

Sete recortes foram selecionados para compor a análise, elencados a seguir. Conforme forem apresentados, será possível observar as relações de linguagem que constroem os sentidos de mulher negra e quais memoráveis se destacam nessa enunciação. Para dar início as análises, apresentamos aqui o primeiro recorte:

R1: Poder Afro - Mulheres Negras transformam a falta de oportunidades em negócios.

No primeiro recorte (R1), o enunciado nos é apresentado como chamada de capa da matéria "Sob Nova Direção". Nesse caso, Mulheres Negras transformam a falta de oportunidades em negócios é uma reescritura de Poder Afro por expansão. Nessa reescritura, temos a expressão Mulheres Negras, que, ao se apresentar como uma reescritura de Poder Afro, coloca as mulheres negras nessa relação de poder. Além disso, nessa reescritura temos uma relação de articulação entre Mulheres Negras e transformam a falta de oportunidade em negócios, articulação que coloca o Poder afro das mulheres negras numa relação direta com aspectos financeiros, já que a falta de oportunidades é transformada por elas em oportunidade de negócios, ou seja, em oportunidades de obter capital financeiro. Nesse caso, o enunciado recorta memoráveis de outras enunciações, como, por exemplo, "dinheiro é poder" ou "quando se tem dinheiro, tem poder" em que circulam sentidos de que o dinheiro constitui relações de poder.

Nesse acontecimento, também podemos perceber o funcionamento de um outro memorável através da articulação de Mulheres negras com falta de oportunidade. Dessa forma, é possível recortar um memorável financeiro que aponta para a realidade financeira na qual a mulher negra está inserida, constituindo o sentido de que a falta de oportunidades nos negócios condiciona historicamente as mulheres negras. Com isso, ao mesmo tempo em que o enunciado propõe enaltecer a mulher negra em favor do poder por ela conquistado, também observamos a presença de um caráter depreciativo que ressalta que os negócios empreendidos por ela não se dão por uma habilidade particular, um ímpeto empreendedor, mas vem de um espaço restrito aos que são pouco valorizados ou que dispõem de poucas oportunidades. Contudo, visto que o acontecimento de linguagem é constituído neste espaço político de enunciação disputado por línguas e falantes, a mulher negra, por conta do poder financeiro atribuído pelo afroempreendedorismo, divide esse espaço, ao modo que aquela que possui dinheiro é incluída e aquela que não possui é excluída.

R2: Sob nova direção - Resgatando e valorizando suas raízes, mulheres negras criam negócios de sucesso, alcançam públicos antes ignorados e impactam suas comunidades. O afroempreendedorismo feminino já é realidade para 4,7 milhões de brasileiras e promete continuar crescendo. 


\title{
$=$ TRAMA $=$
}

Nessa enunciação, a expressão mulher negra é reescriturada, através da repetição, por mulher negra e, em seguida, por brasileiras, por meio da especificação. Essa expressão integrase à primeira parte do enunciado a partir das relações de articulação que estabelece com os termos resgatando e valorizando suas raízes e, posteriormente, criam negócios de sucesso, alcançam públicos antes ignorados e impactam suas comunidades. Nota-se que a articulação com o termo suas raízes recorta um memorável relacionado a aspectos culturais e históricos, visto que, ao enunciar sobre as raízes das mulheres negras, enquanto a identidade e a memória de seu povo, instaura sentidos de resgate e valorização da cultura afro como forma de criar negócios de sucesso, alcançar públicos antes ignorados e impactar suas comunidades.

Na segunda parte do enunciado, a expressão afroempreendedorismo feminino articulase a já é realidade para 4,7 milhões de brasileiras e promete continuar crescendo, em que brasileiras reescritura mulheres negras. Nesse acontecimento, mulheres negras mais uma vez estabelece uma relação enunciativa com aspectos financeiros, ao modo que o termo afroempreendedorismo feminino aponta para aspectos de raça, negócios e gênero, constituindo esse sentido ao confirmar os dados que comprovam a participação das mulheres negras no cenário do empreendedorismo como uma realidade emergente.

Todo o enunciado analisado nos dois parágrafos anteriores é uma ampliação do sentido que se apresenta inicialmente no título, ou seja, o texto é uma reescritura por expansão da expressão Sob nova direção. Essa reescrituração novamente projeta sentidos de que há uma nova configuração no espaço de enunciação, em que se estabelece a afirmação de pertencimento das mulheres negras nos negócios e a redivisão desse espaço para incluí-las. Com isso, segundo Guimarães (2002), entendemos que esse espaço político de enunciação é essencialmente caracterizado por essa disputa, na qual, através do funcionamento da língua, os falantes são divididos pelos direitos ao dizer, ao modo que esse espaço é redividido e transformado pela afirmação do pertencimento dos não incluídos e pela igualdade dos desigualmente divididos.

\begin{abstract}
R3: Por mais representatividade - Empenhada em fazer dar certo, topou. Mas mudou sua apresentação nas redes sociais, fortalecendo seu perfil. Também deixou para trás os fios alisados. As primeiras campanhas apareceram e a nova rede profissional de Regina foi se firmando. Ela percebeu que constantemente era consultada para indicar profissionais da área e que poderia fazer diferença colocando outras modelos negras em evidência. Foi então que abriu as portas da Hutu Casting, agência que insere mais modelos negros no mercado, gerando oportunidades de desenvolvimento econômico para eles. Já são cerca de 300 pessoas no portfólio da empresa.
\end{abstract}

Começamos esta análise destacando que R3 é uma reescritura por expansão de por mais representatividade. Nesse acontecimento, o termo mulher negra aparece apenas reescriturado como elemento elíptico, sem necessariamente estar explícito no texto. Há, então, uma omissão do termo, no qual este é percebido pela conjuntura linguística do enunciado e também pelos aspectos imagéticos que constituem a matéria. Assim, inicialmente, mulher negra reescritura-se por elipse, visto que, mesmo implícita, encontra-se presente no texto camuflada pelos verbos "mudou", "fortalecendo" e "deixou". Com isso, estabelece uma relação com as expressões mudou sua apresentação nas redes sociais, fortalecendo seu perfil e também deixou para trás os fios alisados. Nota-se que estas relações de articulação constituem o sentido de representatividade, ao modo que a necessidade de apresentar-se de forma diferente significa uma maneira de fortalecer seu perfil e assumir os fios naturais para evidenciar a estética afro, a fim de melhor representar um grupo. 


\section{$=\mathrm{T} R A M A=$}

Posteriormente, mulher negra é reescriturada pelo pronome ela, através do mecanismo de substituição, ao modo que também articula-se com percebeu que constantemente era consultada para indicar profissionais da área e poderia fazer diferença, em que colocando outros modelos negros em evidência reescritura a expressão poderia fazer diferença. Nesse momento, o enunciado novamente projeta o sentido de representatividade, visto que, a partir da inclusão de mais modelos negros no mercado de trabalho, constitui uma forma de representação social da população negra na moda, redesenhando esse espaço. Dessa forma, ao modo que os colocar em destaque configura uma diferença, também podemos recortar um memorável que estabelece sentidos de que o padrão estético em evidência, até então, na televisão, nas revistas e nas campanhas publicitárias, era o de pessoas brancas.

R4: Público certo - Inovação e criatividade são as palavras que guiam o trabalho da museóloga Débora da Luz Nascimento, 29 anos. Em 2017, com o sócio Bruno Brigida, a paulistana fundou o Clube da Preta para levar aos consumidores produtos de marcas pequenas e médias criadas por pessoas negras. Havia notado que esses empreendedores, concentrados nas periferias das cidades, tinham dificuldade para escoar sua produção. Começou reunindo apenas cinco assinaturas. Agora já são 500, a maioria de moda e beleza.

Em R4, embora a expressão mulher negra não esteja presente no enunciado, ela aparece reescriturada por substituição por Débora da Luz Nascimento que, por sua vez, reescritura-se por paulistana e, através de elipse, por havia e começou. A partir dessas relações enunciativas, podemos destacar que as expressões descritas articulam-se inicialmente com museóloga e fundou o Clube da Preta. É interessante observar que preta também é uma reescritura de mulher negra, e sequencialmente com para levar aos consumidores produtos de marcas pequenas e médias criadas por pessoas negras. Posteriormente, é estabelecida uma articulação com esses empreendedores que se articula com tinham dificuldade para escoar sua produção. Por fim, a nomeação Débora, através da elipse de começou reunindo, também articula-se com apenas cinco assinaturas e agora já são 500 .

A partir da análise descrita acima, podemos retomar sentidos constituídos em outros recortes. Ao fundar um clube de assinaturas para consumidores negros, mobiliza-se o sentido de afroempreendedorismo feminino, ao modo que, ao priorizar marcas pequenas e médias criadas por negros, podemos observar a retomada do sentido de representatividade. Em seguida, ao enunciar sobre a dificuldade da população das periferias para escoar sua produção, rememoramos o sentido de falta de oportunidade nos negócios que tratamos no primeiro recorte. Também podemos encontrar novamente um memorável financeiro presente que se destaca através dos sentidos que são constituídos na ascensão de crescimento nos negócios e atribui-lhe poder, em que Débora passa de cinco a 500 assinaturas.

O texto que acabamos de analisar é uma reescritura de público certo - título atribuído a essa enunciação. Desse modo, observamos que levar produtos de beleza e moda para negros, priorizando marcas criadas por pessoas negras e empreendedores das periferias, ajudam a construir o sentido de público certo.

R5: Pratos que ensinam - Para aproveitar ao máximo suas habilidades e ensinar as pessoas, ela oferece oficinas de culinária fora da Bahia. Mas há outra conquista a destacar. Cada vez mais, Lili vem deixando de lado o título de Chef para ser chamada de empreendedora. 'Há cinco anos, eu estava vendendo comida na praia e, agora, estou reformando meu restaurante para ampliar o espaço. Isso é grande', diz, emocionada. 


\section{$=\mathrm{T} R A M A=$}

Em R5, mulher negra encontra-se reescriturada, através da substituição, pelo pronome ela, Lili, Chef e empreendedora. Além disso, mulher negra também é reescriturada, através da elipse, por estava vendendo e estou reformando, em que a expressão apresenta-se por meio do pronome eu. Neste último caso, é interessante ressaltar que, embora a pessoa que dá origem ao dizer acredite que enuncia a partir de uma tomada de consciência ou que controle o que diz, este eu é tomado pelo agenciamento que gera no Locutor um esquecimento de que ele fala de um lugar social do dizer, ou seja, acontece um apagamento de qual lugar o Locutor enuncia, seja ele Chef, empreendedora, mãe, etc. Nessa cena enunciativa, o Locutor é representado por um lugar de dizer de enunciador, ou mais especificamente, neste caso, por um enunciador-individual, que enuncia enquanto representação da individualidade do dizer e coloca a enunciação como independente da história (GUIMARÃES, 2002).

As reescrituras de mulher negra inicialmente estabelecem uma relação de articulação com para aproveitar ao máximo suas habilidades e ensinar as pessoas e com oferece oficinas de culinária fora da Bahia. Na sequência, o termo mas é uma articulação que relaciona-se com há outra conquista a destacar, projetando uma ressalva e que, ao mesmo tempo em que Lili articula-se com vem deixando de lado o título de Chef para ser chamada de empreendedora, a palavra conquista reescritura empreendedora. Desse modo, podemos observar que oferecer oficinas de culinária fora da Bahia e ensinar as pessoas em outros estados representa uma conquista. Outra conquista destacada no enunciado é determinada pela condição de tornar-se empreendedora.

No acontecimento que descreveremos agora, mulher negra articula-se com estava vendendo comida na praia e agora, estou reformando meu restaurante para ampliar o espaço, as quais estas expressões são reescrituradas, através da expansão, por isso é grande. Neste caso, deixar de vender comida na praia para ampliar seu restaurante constitui sentido de algo admirável, de um feito grandioso. Este sentido estabelece, mais uma vez, uma relação com aspectos financeiros, visto que determina o poder, não por suas habilidades culinárias ou por estar na praia vendendo comida, mas por conseguir sucesso ao empreender.

Nesse recorte, a reescrituração do texto pelo título - pratos que ensinam - projeta o sentido de que as habilidades de cozinheira atribuíram condições para aprender outra função: empreender.

R6: Mais oportunidades - Durante a faculdade, a paulistana Liliane Rocha, 37 anos, conseguiu seu primeiro estágio em uma multinacional. Ela atribuiu a oportunidade a uma gestora preocupada em incluir minorias no ambiente corporativo. Depois dessa experiência, passou por diferentes companhias até assumir a função de representante da América Latina em uma mineradora. Apesar do aumento salarial, ela não ocupava formalmente o cargo. 'Percebi que a promoção poderia não sair e que seria difícil chegar ao topo', conta Liliane. Resolveu então deixar a estabilidade do emprego para empreender.

Em R6, a expressão mulher negra tem um funcionamento parecido com o que observamos em R5. Aqui, mulher negra também encontra-se reescriturada por um nome próprio - Liliane Rocha - que, por sua vez, é reescriturada por paulistana, ela, Liliane e, através de elementos elípticos, também pode ser percebida a partir das palavras passou, percebi e resolveu. Inicialmente, mulher negra está articulada com as expressões conseguiu seu primeiro estágio em uma multinacional e atribuiu a oportunidade a uma gestora preocupada em incluir minorias no ambiente corporativo, em que oportunidade reescritura estágio em uma multinacional e a palavra minoria estabelece uma relação de sentido com mulheres negras, determinando que estas constituem apenas uma pequena parte naquele ambiente de trabalho. 


\section{$=\mathrm{T} R A M A=$}

É interessante perceber também que incluir minorias estabelece uma relação com aspectos políticos, pois pode ser determinada pelo sentido de ações afirmativas, buscando reverter uma situação de desvantagem que acomete um grupo.

Mulher negra também articula-se com passou por diferentes companhias e até assumir a função de representante da América Latina em uma mineradora. A expressão apesar do aumento salarial é uma articulação com ela não ocupava formalmente o cargo, e, em seguida, percebi que a promoção poderia não sair e que seria difícil chegar ao topo e deixar a estabilidade do emprego para empreender também estabelecem uma relação de articulação com mulher negra. A partir dessas articulações, também é possivel recortar um memorável relacionado a aspectos financeiros, pois constitui sentidos de a experiência de trabalho não atribuir poder à mulher negra, visto que, apesar do aumento salarial, faltavam-Ihe oportunidades de crescer dentro da empresa. O que atribui visibilidade a esta mulher está na condição de empreender. A circulação desses sentidos se confirma também a partir da reescrituração do texto pelo título - por mais oportunidade, significando enquanto estabelece uma relação em que tornar-se empreendedora pode atribuir mais chances da mulher negra chegar ao topo e crescer financeiramente.

R7: De olho nos desejos - Cursar ensino superior era o sonho de Camila Reis, 30 anos. Ela seria a primeira de sua família a frequentar a faculdade. Esperava assim encontrar um bom emprego. Na reta final dos estudos de gestão comercial, o impeto empreendedor surgiu ao constatar a falta de opções de produtos de qualidade para cabelos crespos, especialmente os óleos vegetais.

Em R7, mulher negra é reescriturada, através da substituição, por Camila Reis e pelo pronome ela e articula-se com cursar ensino superior e primeira de sua família a frequentar a faculdade, em que a palavra sonho reescritura cursar ensino superior. Nesse acontecimento, podemos destacar a rememoração de sentidos presentes em outras análises, relacionados à falta de oportunidades. Ser a primeira da família a ir para a faculdade determina uma maior acessibilidade à educação no país e, mais uma vez, redivide este espaço de enunciação o qual a população negra, antes com acesso limitado à educação, agora reafirma seu pertencimento numa disputa pela igualdade daqueles que são excluídos dessa normatividade.

Em seguida, a expressão mulher negra aparece a partir da reescritura, através da elipse, das palavras esperava e constatar. Estas reescrituras, por sua vez, estão articuladas com as expressões esperava assim encontrar um bom emprego, o ímpeto empreendedor surgiu ao constatar a falta de opções de produtos de qualidade para cabelos crespos. A partir dessas relações, a circulação de sentidos aponta que a ação de empreender surgiu a partir de uma necessidade específica de pessoas negras, em que empreender é determinado por encontrar um bom emprego. Além disso, a falta de produtos de qualidade para cabelos crespos recorta um memorável de exclusão, instaurando o sentido de que as necessidades desse grupo são postas à margem pelo mercado. Constatar essa falha possibilita alcançar públicos antes ignorados e impactar comunidades, configurando os sentidos que determinam o afroempreendedorismo em análises anteriores.

Nesta análise, a expressão de olho nos desejos reescritura R7. Com isso, podemos observar que o sonho de entrar para a faculdade e encontrar um bom emprego determinam o sentido de desejos.

Dando continuidade à análise, de acordo com as relações linguísticas presentes nos recortes apresentados acima, foi possível chegar a uma representação da significação produzida enunciativamente neste acontecimento, mobilizando o conceito de Domínio Semântico de Determinação (DSD), como uma interpretação do próprio processo de análise. 


\section{$=$ TRAMA $=$}

A partir dessa configuração, podemos obter uma visualização gráfica de como o sentido de uma palavra é determinado por outras expressões, representando essas relações semânticas por meio da utilização de sinais $\vdash_{T}^{\perp} \dashv$, em que os termos situados nas extremidades de cada traço estão a atribuir sentido. (GUIMARÃES, 2009).

Temos, assim, o seguinte DSD:

representatividade

$\perp$

mulher negra + afroempreendedorismo + poder afro - poder financeiro

T

mais oportunidades

Contudo, a expressão mulher negra é determinada pela palavra afroempreendedorismo que é determinado por representatividade, mais oportunidades e por poder afro. Este último, por sua vez, é determinado por poder financeiro. Esta relação de determinação nos chama atenção na medida em que o poder afro se constitui a partir do poder financeiro, visto que, em todas as análises apresentadas, percebemos que o destaque atribuído à mulher negra nesse acontecimento não se dá pela capacidade de mudar realidades a partir do seu talento, história de vida ou experiências, mas por obter sucesso ao tornar-se empreendedora e, com isso, ter dinheiro. Este lugar de enaltecimento da mulher negra em que a revista the agrega poder, também indica que ela tem valor ao passo que conquista capital financeiro. O poder não está nas suas ações em si, mas no fato de evoluir e tornar-se "alguém" a partir de um ideal capitalista de que se sobressai aquele que tem plenas possibilidades de produção e consumo, ou seja, que faz circular o capital.

\section{CONSIDERAÇÕES FINAIS}

Pelas análises da expressão mulher negra na matéria veiculada na Revista Cláudia, no acontecimento de linguagem "Sob Nova Direção", observamos que as relações enunciativas instauram sentidos de que o Poder Afro destacado pela Revista é determinado pelo poder monetário. Desse modo, a matéria publicada no mês em que se celebra o Dia da Consciência Negra que, inicialmente, parece apontar para a valorização do direito da mulher negra, nos mostra um outro posicionamento ao tratar do afroempreendedorismo. Há nessa enunciação um destaque da prática de empreender e um apagamento acerca de outras questões importantes para as mulheres negras.

Nessa direção, apesar de evidenciar e apresentar depoimentos de mulheres negras que transformaram suas realidades através do afroempreendedorismo, a visibilidade dessas mulheres não é atribuída ao talento que desenvolveram, pela luta que travaram para conquistar esses espaços, ou ainda pelos obstáculos impostos socialmente a estas mulheres, mas pelo fato de conquistarem poder econômico ao empreenderem.

Contudo, observamos que os sentidos constituídos nessa matéria da Revista Cláudia, para tratar sobre o poder das mulheres negras nos negócios, nos apresentam uma abordagem simplista da questão, impedindo que se estabeleça uma discussão mais complexa sobre como a intersecção das categorias de gênero, raça e classe impactam as dificuldades dessas mulheres conquistarem o mercado de trabalho. O ímpeto empreendedor é suficiente para que mulheres negras mudem suas realidades? Quais oportunidades Ihes são dadas? Elas possuem 
capital financeiro para investir no empreendedorismo? Responder tais questionamentos, por exemplo, propõe uma abordagem mais profunda da questão e nos possibilita melhor conhecer a realidade das mulheres negras, dando voz também às experiências de classes sociais desfavorecidas para então pensar possíveis formas de sociabilidade.

\section{REFERÊNCIAS}

CRENSHAW, Kimberlé. (2004). A interseccionalidade na discriminação de raça e gênero. In: VV.AA.

Cruzamento: raça e gênero. Brasília: Unifem.

CRENSHAW, Kimberlé. Documento para o encontro de especialistas em aspectos da discriminação racial

relativos ao gênero. Revista Estudos Feministas, v.10, nº 1, 2002, p.171-189.

GUIMARÃES, Eduardo. A Enumeração: funcionamento enunciativo e sentido. Cadernos de estudos

linguísticos, Campinas, 51 (1): 49-68, Jan./Jun. 2009.

GUIMARÃES, Eduardo. Semântica do acontecimento: um estudo enunciativo da designação. Campinas, SP:

Pontes, 2002.

GUIMARÃES, Eduardo. Semântica: enunciação e sentido. Campinas, SP: Pontes Editores, 2018.

GUIMARÃES, Eduardo. Os limites do sentido: um estudo histórico e enunciativo da linguagem. Campinas, Pontes, 1995.

HOOKS, bell. O feminismo é para todo mundo: políticas arrebatadoras. Tradução Bhuvi Libânio. - 6 ed. - Rio de Janeiro: Rosa dos Tempos. 2019.

KILOMBA, Grada. Plantation Memories: Episodes of Everyday Racism. Münster: Unrast Verlag, 2012 apud RIBEIRO, 2019.

Poder Afro: Revista Cláudia. São Paulo, SP: Grupo Abril, 2019-Mensal.

RIBEIRO, Djamila. Lugar de Fala. Coleção Feminismos Plurais. São Paulo: Pólen, 2019.

Recebido em 29-10-2020 Revisões requeridas em 09-01-2021

Aceito em 15-01-2021 